\title{
O PAPEL DO PROFISSIONAL DE EDUCAÇÃO FÍSICA NA VIDA DO
}

\section{AUTISTA}

\author{
Betina Maria Martins Lopes ${ }^{1}$ \\ . Fernando Duarte Cabral ${ }^{2}$
}

RESUMO: O presente trabalho tem como meta refletir a respeito do desenvolvimento do Profissional em Educação Física na vida do autista, pontuado algumas leis que garantem o direito de alunos com necessidades educacionais especiais na rede regular de ensino, nas esferas municipais, estaduais e particulares, de acordo com a Lei de Diretrizes e Bases da Educação Nacional de 1986. Pontua-se um breve conceito de inclusão social, necessidades educacionais especiais e integração. Para que haja de fato uma educação inclusiva é imprescindível que os professores busquem capacitação, aperfeiçoamento e formação continuada, a fim de proceder à mediação ao receber alunos com necessidades educacionais especiais, visando um ensino que respeite as diferenças e particularidades de cada indivíduo. $\mathrm{O}$ autismo é caracterizado por anormalidades no desenvolvimento, que ocorrem antes dos três anos de idade, percorrendo por toda a vida de um indivíduo. Dentre destas anormalidades, destacam-se três áreas do desenvolvimento: a interação social, linguagem e comunicação, presença ou repertório de comportamentos e interesses restritos, estereotipados e repetitivos. A educação física tem o objetivo de estimular o desenvolvimento psicomotor e, como princípio fundamental, despertar a criatividade dos educadores, além de contribuir para a formação integral do educando. Tem como finalidade auxiliar no desenvolvimento físico, mental e afetivo. Com a regularidade da prática de atividade física, crianças com Transtorno do Espectro do Autismo (TEA) aprimoram comandos simples, proporcionando uma melhora na coordenação motora e comunicação. $O$ presente estudo tem como objetivo analisar o desenvolvimento do autista e a importância da atividade física para o mesmo. Após a pesquisa bibliográfica, pôde-se perceber que a atividade física direcionada ao autista, juntamente com o método de intervenção adequado, leva a melhora da qualidade de vida destas crianças.

Palavras-chave: Educação física. Autista. Intervenção.

ABSTRACT: The present work aims to reflect on the development of the Physical Education Professional in the life of the autistic person, pointing out some laws that

\footnotetext{
${ }^{1}$ Graduanda do Curso de Educação Física pela Faculdade Unibrás de Goiás- FACBRÁS, E-mail: betamaria1979@hotmail.com.

${ }^{2}$ Professor orientador. Faculdade Unibrás de Goiás- FACBRÁS.
} 
guarantee the right of students with special educational needs in the regular school system, in the municipal, state and private spheres, according to with the National Education Guidelines and Bases Law of 1986. A brief concept of social inclusion, special educational needs and integration is highlighted. For there to be truly inclusive education, it is essential that teachers seek training, improvement and continuing education, in order to mediate when receiving students with special educational needs, aiming at teaching that respects the differences and particularities of each individual. Autism is characterized by developmental abnormalities that occur before the age of three and last through an individual's lifetime. Among these abnormalities, three areas of development stand out: social interaction, language and communication, presence or repertoire of restricted, stereotyped and repetitive behaviors and interests. Physical education aims to stimulate psychomotor development and, as a fundamental principle, to awaken the creativity of educators, in addition to contributing to the student's integral training. Its purpose is to assist in physical, mental and affective development. With the regular practice of physical activity, children with Autism Spectrum Disorder (ASD) improve simple commands, providing an improvement in motor coordination and communication. This study aims to analyze the development of autistic individuals and the importance of physical activity for them. After the literature search, it could be seen that physical activity aimed at the autistic, together with the appropriate intervention method, leads to an improvement in the quality of life of these children.

Keywords: Physical education. Autistic. Intervention.

\section{INTRODUÇÃO}

A atividade física é um comportamento para a prevenção de doenças e manutenção da saúde e deve enfatizar a participação, decisão, autonomia e independência. Portanto, a educação física oferecida pelas escolas deve incluir o corpo, o movimento e a ludicidade como aspectos educacionais indissociáveis e oferecer oportunidades educacionais adequadas ao desenvolvimento integral e a busca de uma objetiva participação e integração social (WINNICK, 2004)

A escola com a responsabilidade de formar profissionais mais preparados para atender a diversidade na vida em sociedade, vem constantemente fazendo mudanças na sua organização curricular, principalmente no que se refere à inclusão de alunos com necessidades educacionais especiais (NEE). É um grande desafio aos professores o processo de inclusão dos alunos com necessidades educacionais especiais, pois cabe a eles construírem novas propostas de ensino, atuar com um 
olhar diferente em sala de aula, sendo o agente facilitador do processo de ensinoaprendizagem

Muitas vezes os profissionais apresentam resistência quando o assunto é mudança, proporcionando uma grande discussão de como incluir metodologias no processo de ensino-aprendizagem que proporcione a inclusão de alunos com necessidades especiais dentro do âmbito educacional e físico. Quanto mais conhecemos determinado fato ou assunto, mais nos sentimos seguros diante dele. $\mathrm{O}$ novo gera insegurança e instabilidade, exigindo reorganização e mudança. É comum sermos resistentes ao que nos desestabiliza. Sem dúvida, as ideias inclusivas causaram muita desestabilidade e resistência (MINETTO, 2008, p.17).

Assim, cabe aos profissionais procurarem novas posturas e habilidades que permitam compreender e intervir nas diferentes situações que se deparam, além de auxiliarem na construção de uma proposta inclusiva, fazendo com que haja mudanças significativas pautadas nas possibilidades e com uma visão positiva das pessoas com necessidades especiais.

Para que os objetivos do processo de inclusão sejam alcançados, deve haver mudanças nesse processo dentro do contexto escolar, que são realizadas através da reflexão comprometida e responsável pelos envolvidos referente à realidade inclusiva.

Considerando a importância do professor no processo de ensino educativo e inclusivo, os objetivos deste trabalho foram analisar e avaliar sua qualificação e habilidades frente à inclusão de alunos com necessidades especiais e o processo de aprendizagem proposto para tais alunos, a fim de facilitar a inclusão desses sujeitos de maneira eficaz e satisfatória.

A educação especial é resultado da mudança de opinião da sociedade, da melhoria das políticas públicas, da pressão imposta ao Estado pelos movimentos sociais, na consolidação de seus direitos como sujeitos sociais e, principalmente na criação de um novo modelo de projeto educativo para a efetivação da educação inclusiva nas escolas. 


\section{2- O PAPEL DO PROFESSOR NA EDUCAÇÃO INCLUSIVA}

A implementação da inclusão escolar de forma adequada na educação infantil é importante, pois é nesta faixa etária que as crianças desenvolvem suas potencialidades de maneira mais significativa, mesmo as que apresentam deficiências.

Portanto é nesta primeira etapa da educação básica que devemos aprimorar a forma de concretizar a inclusão escolar mediante ações eficazes que possam garantir o direito de participação efetiva da criança no cotidiano escolar. Para que as escolas atendam ao processo de inclusão, os alunos com necessidades educacionais especiais devem ser incluídos no ensino regular, onde o cujo processo de ensino precisa de uma revisão, a fim de atender as demanda individuais de cada aluno, independentemente de suas particularidades e diferenças, de modo a adequar e organizar o Currículo Escolar e o Projeto Político Pedagógico da instituição, contemplando a diversidade de sua comunidade escolar, formando um equilíbrio entre o desenvolvimento dos conteúdos previstos e a socialização de todos os envolvidos. Um currículo centrado fundamentalmente nos conteúdos conceituais e nos aspectos mais acadêmicos, que propõe sistemas de avaliação baseados na superação de um nível normativo igual a todos, lança ao fracasso alunos com mais dificuldades para avançar nestes âmbitos.

A inclusão escolar é a oportunidade para que de fato a criança com deficiências não esteja à parte, realizando atividades meramente condicionadas e sem sentido. Para haver a inclusão das crianças com deficiências no processo educativo se faz necessário reconhecer a criança como pessoa que possui direito à escolarização e em seguida como criar estratégias educativas que possam contemplar os objetivos traçados, tanto para as crianças com deficiências, como para as sem deficiências.

A escola como suporte para a educação inclusiva depende de adaptações de grande e médio porte. Os de grande porte competem aos órgãos federais, estaduais e municipais de educação; as de pequeno porte são mudanças que cabem das iniciativas dos professores, que devem buscar recursos para ampliar sua qualificação, com o intuito de inserir esses alunos de forma eficaz e humana, com direitos e tratamentos iguais na educação. A LDB - Lei de Diretrizes e Bases (BRASIL, 1996) destaca a 
importância da preparação adequada dos professores como pré-requisito para a inclusão, determinando que os sistemas de ensino devam garantir professores capacitados e especializados para a integração e adaptação dos educandos com NEE, no ensino regular.

O domínio dos conhecimentos pedagógicos pelos professores torna-se essencial, pois assim, poderão desenvolver suas atividades de ensinar, planejar e avaliar o ensino para seus alunos. A atividade de ensinar é complexa e exige professores com conhecimentos atualizados. Desta forma, o grande desafio para as Faculdades e Universidades é formar educadores preparados para construir estratégias de ensino e adaptar atividades e conteúdos, não só para os alunos considerados especiais, mas para todos os integrantes de sua classe.

Aranha (2000, p. 08) aponta a necessidade de se capacitar os profissionais, no sentido de se prover suporte técnico, didático e pedagógico, argumentando que "só assim se obterá um fazer apoiado no saber e uma construção de conhecimentos originada no fazer".

O movimento mundial pela educação inclusiva é uma ação social, cultural, pedagógica e política, iniciada em defesa dos direitos de todos os alunos, compartilhando e aprendendo, sem discriminação. A educação especial é resultado da mudança de opinião da sociedade, da melhoria das políticas públicas, da pressão imposta ao Estado pelos movimentos sociais, na consolidação de seus direitos como sujeitos sociais e, principalmente na efetivação da Educação Inclusiva nas escolas.

No Brasil, a formação de professores de educação especial teve início na década de 50 em cursos de nível médio, perdurando até o final dos anos 6o. Nesta época evidenciava-se a presença de duas tendências adotadas pela formação: a tendência educacional, que caracterizou os cursos para o ensino a deficientes auditivos e deficientes visuais e a médico-pedagógica, que contemplava o ensino para deficientes físicos e mentais e caracterizava-se pelo aspecto terapêutico e tecnicista. A formação de professores de educação especial é elevada do nível médio ao superior, nos anos 70, onde os cursos de Pedagogia passam a oferecer a Habilitação em Educação Especial. Neste período são ofertados os primeiros cursos de especialização, 
como alternativa para a formação de professores de educação especial. (MAZZOTTA, 1999).

Para atuar na educação especial, o professor deve ter como base na sua formação, inicial e continuada, conhecimentos gerais para o exercício da docência e conhecimentos específicos da área.

Mantoan (2006) afirma que os professores esperam aprender uma prática inclusiva, isto é, uma formação que lhes permita aplicar esquemas de trabalho prédefinidos nas suas salas de aulas, garantindo a solução dos problemas que pensam encontrar nas escolas inclusivas. A docência tornou-se complexa e diversificada, já não é mais uma profissão pautada apenas na transmissão do conhecimento acadêmico ou da transformação de conhecimentos científicos em saberes escolares.

As mudanças, visando à formação de professores para atuar na educação inclusiva, podem contribuir expressivamente para que as transformações nas escolas aconteçam de fato. O que se pretende é uma pedagogia centrada no aluno que por sua vez, ocasione a construção de uma sociedade que respeite a dignidade e as diferenças humanas. Esta e a missão dos responsáveis que atuam no campo da definição de políticas educacionais inclusivas.

\section{3- METODOLOGIA DA PESQUISA}

Os procedimentos metodológicos utilizados no plano de intervenção tiveram por base a técnica de pesquisa-ação e foram realizados através de entrevista com educadoras. A pesquisa-ação é um tipo de metodologia de pesquisa na qual o pesquisador deve estar empenhado em solucionar algum problema através de uma ação. Portanto para este tipo de pesquisa, o problema a ser solucionado torna-se objeto de estudo.

Assim sendo, tanto o pesquisador quanto o grupo pesquisado interagiram de modo participativo, desenvolvendo as idéias propostas no plano de pesquisa. Para a pesquisa-ação, é preciso que ao final do processo haja algum tipo de transformação do grupo envolvido, gerando assim a solução para o problema em questão, conforme os objetivos específicos da pesquisa. Por esse motivo, durante um determinado estudo, 
poderão ocorrer ajustes progressivos nos planejamentos da investigação, se assim for necessários.

Nessa perspectiva de estar aberto a conhecer o outro, Freire (2005, p. 58) em sua obra Pedagogia da Autonomia afirma que "o ideal é que na experiência educativa, educandos, educadoras e educadores, juntos 'convivam' de tal maneira com os saberes que eles vão virando sabedoria. Algo que não é estranho a educadores e educadoras.”. Com base na Resolução CNE/CEE no 02/200I, a educação especial oferta apoios e serviços especializados aos alunos com necessidades educacionais especiais.

\subsection{O autismo e a educação física - formas de abordagem e intervenção}

O autismo é um transtorno que surge precocemente nos primeiros anos de vida e que envolve perda significativa na comunicação, na socialização e na capacidade imaginativa. Para Calegaro, Stolaruk e Zeni (s/d). Em complementação, segundo Assumpção Jr et al. (1999, s/p) "seu surgimento ocorre antes dos 3 anos de idade, com prevalência estimada de 4 a 5 / Ioooo e predominância no sexo masculino (3 a 4 para I), sendo relacionado a fatores pré, peri e pós-natais”.

De acordo com as estatísticas no Brasil deve haver de 65.000 a 195.000 autistas, baseando em estudos realizados nas proporções internacionais, já que nenhum levantamento deste tipo foi realizado no país. As crianças autistas, na maioria dos casos apresentam ausência ou atraso da linguagem oral, o uso repetitivo da linguagem, dificuldades no contato visual com o outro, falta de interesse em relacionamentos entre os pares, ausência de espontaneidade e a definição em determinados objetos. Para Ellis, ficam claro os déficits de interação social, comunicação e imaginação social e os comportamentos rígidos, repetitivos são o núcleo central do espectro autístico, ainda que apresentem outras tantas características variáveis.

Em relação às características sócio-emocionais os indivíduos autistas apontam-se geralmente, isolados, agressivos, desinteressados; abdicam de maiores contatos físicos e afetivos; têm movimentos inapropriados; não evidenciam medo de 
perigos reais; resmungam; riem inadequadamente; apresentam hábitos estranhos na alimentação; têm crises de choro e angustia sem motivos aparentes.

A Lei no 12.764, que institui a Política Nacional de Proteção dos Direitos da Pessoa com Transtorno do Espectro Autista, sancionada em dezembro de 2012, traz com sigo que os autistas são considerados oficialmente pessoas com deficiência, tendo direito a todas as políticas de inclusão do país, entre elas, as de educação, assim o autismo passou a ser considerado legalmente como uma deficiência, e toda escola pública, estando preparada ou não, passa a ter obrigação de incluir os alunos com esse tipo de deficiência. Já de acordo com a ıo a $^{\mathbf{a}}$ Classificação Internacional de Doenças (CID-ıo) de I991, o autismo recebe a classificação F84-o, sendo considerado como um Transtorno Invasivo do Desenvolvimento anormal e comprometido, manifesto antes dos três anos de idade.

As crianças e jovens com Necessidades Educacionais Especiais (NEE) devem ter acesso às habilidades físicas regulares e a elas se devem adequar, através de uma pedagogia centrada na criança, jovem ou adulto, capaz de ir ao encontro destas necessidades. Os ambientes regulares, seguindo esta orientação inclusiva, constituem os meios mais capazes para combater as atitudes discriminatórias, criando comunidades abertas e solidárias, construindo uma sociedade inclusiva e atingindo a educação para todos.

O profissional/professor é o mediador entre o indivíduo e sua interação e cabe a ele promover situações pedagógicas em que as pessoas com necessidades educacionais especiais superem o senso comum e avance em seu potencial humano afetivo, social e intelectual, quebrando as barreiras que se impõem.

Assim sendo, as relações entre profissionais de educação física e discentes envolvem comportamentos intimamente relacionados, em que as ações de um desencadeiam ou promovem as do outro. Dessa maneira, o aluno não é um depósito de conhecimentos memorizado, como se fosse um fichário ou uma gaveta. O aluno é um ser capaz de pensar, refletir, discutir, ter opiniões, participar, decidir o que quer e o que não quer. 


\section{4- INCLUSÃO - AUTISMO E SEUS DIVERSOS ESPECTROS}

Para que a educação inclusiva seja uma realidade, para além de uma mudança de mentalidades, no que diz respeito ao acesso e ao sucesso da educação para todos, é necessário criar condições e recursos adequados a cada situação. Um dos recursos que Porter preconiza é a criação de "professores de métodos e recursos", nomeados para as escolas de acordo com o número de alunos existente (I/I50 a 200) para atuar como “consultor de apoio junto do professor da classe regular é responsável por ajudá-lo a desenvolver estratégias e atividades que apoiem a inclusão dos alunos com necessidades especiais na classe regular".

Nos Parâmetros Curriculares Nacionais, definiram-se adaptações curriculares como "estratégias e critérios de atuação docente, admitindo decisões que oportunizam adequar a ação educativa escolar às maneiras peculiares de aprendizagem dos alunos, considerando que o processo ensino aprendizagem pressupõe atender à diversificação de necessidades dos alunos na escola. " Penso que para o estabelecimento de uma inclusão efetiva para alunos portadores de Transtornos Invasivos do Desenvolvimento, seria necessário discutir sobre que "suporte necessário à ação pedagógica" se está falando, bem como quais seriam as “adaptações curriculares” necessárias. Uma escola realmente inclusiva estaria disposta a lidar com a heterogeneidade e com a diversidade. Além disso, um dos principais objetivos da inclusão é que o professor exclua a visão de incapacidade das pessoas com necessidades especiais e que promova atividades que valorizem o respeito às diferenças $e$ às inteligências múltiplas. Para isso, muitas vezes o planejamento das aulas incluirá jogos, músicas, atividades em grupo, desenhos, entre outros exemplos.

A qualificação profissional do docente é extremamente importante para efetiva inclusão dos alunos. Contudo, muitas vezes o tempo e os recursos financeiros impedem o curso de uma pós-graduação. Por isso, é válido contar com o auxílio de outros meios de ensino, como a internet.

Atualmente, já existem excelentes cursos online e gratuitos que auxiliam o professor a se preparar para receber alunos com necessidades especiais. Além disso, a 
busca por outras fontes de informações também é imprescindível, portanto, mesmo quem já cursou uma pós, pode estudar gratuitamente e adquirir mais conhecimento.

\section{I- ESTRATÉGIAS DE INTERVENÇÃO PARA CRIANÇAS AUTISTAS}

$\mathrm{Na}$ busca de melhores métodos de ensino para as crianças com autismo primeiramente devemos começar por "identificar o que devemos ensinar a uma criança com autismo, o que é uma tarefa complicada e delicada, já que elas não se ajustam às formas habituais de avaliação".

Depois de diagnosticado os critérios adotados deveram apresentar um modelo mais simples, é uma ajuda muito útil quando não encontrarmos outra mais eficaz. Segundo Jordan, o professor deve sistematizar e organizar os métodos de ensino com a finalidade de ensinar de forma eficaz.

Todas as formas de avaliação dar-nos-ão informações suficientes para definição dos objetivos, se forem escolhidos em função dos seguintes critérios: adequação à evolução da criança; apresentação de evolução normal; funcionalidade, na medida do possível e adaptação da criança com autismo a ambientes naturais. A seleção de objetivos e tarefas nesta área proporcionará estratégias de aprendizagem para futuros objetivos e situações naturais mais complexas, além de fornecer objetivos específicos de desenvolvimento.

Os professores de um modo geral se apresentam dificuldades na forma de conflito ao lidar com o "diferente". O professor tende, então, a adotar estratégias que, de certa forma inibem a expressão dos "sintomas autistas" (Ex: "manter o aluno ocupado"), mais como uma tentativa de "dominar" tais sentimentos do que como uma prática pedagógica, voltada para as necessidades do aluno. Idéias pré-concebidas, principalmente a partir da mídia, influenciam as expectativas do professor sobre o desempenho de seus alunos, afetando a eficácia de suas ações quanto à promoção de habilidades.

As práticas educacionais desenvolvidas nesse período e que promovem a inclusão na escola regular dos alunos com deficiência (física, intelectual, visual, auditiva e múltipla), com transtorno global do desenvolvimento e com altas 
habilidades, revelam a mudança de paradigma incorporada pelas equipes pedagógicas. Essas ações evidenciam os esforços dos educadores em ensinar a turma toda e representam um conjunto valioso de experiências.

A educação especial como modalidade de ensino ainda está se difundindo no contexto escolar. Para que se torne efetiva, precisarão dispor de redes de apoio que complementem o trabalho do professor. Atualmente, as redes de apoio existentes são compostas pelo Atendimento Educacional Especializado (AEE) e pelos profissionais da educação especial (intérprete, professor de Braille, etc.) da saúde e da família.

Quando os procedimentos de ensino privilegiam a construção coletiva e são organizados com base nas necessidades dos alunos, leva-se em conta os diferentes estilos, ritmos e interesses de aprendizagem de cada um. Ou seja, todos os estudantes são diferentes e suas necessidades educacionais poderão requerer apoio e recursos diferenciados.

A avaliação da aprendizagem, por sua vez, deverá ser coerente com os objetivos, as atividades e os recursos selecionados. Se o processo de aprendizagem for redimensionado, o procedimento de avaliação também deverá ser.

\section{2 - Instrumentos avaliativos no caso dos autistas}

No caso do Autismo há dificuldade de se trabalhar com jogos por possuírem dificuldade de compreensão de regras estabelecidas, além de apresentarem em sua maioria déficit de coordenação motora. Sabe-se também que disfunções motoras podem contribuir para um atraso de linguagem e comunicação.

Os instrumentos de avaliação devem informar o desenvolvimento atual da criança, a forma como ela enfrenta determinadas situações de aprendizagem, os recursos e o processo que faz uso em determinada atividade. Conhecer o que ela é capaz de fazer, mesmo que com a mediação de outros, permite a elaboração de estratégias de ensino próprias e adequadas a cada aluno em particular.

A linguagem/comunicação é fundamental para que haja interação social e cultural. Contudo, é um dos maiores obstáculos do autista. Embora muitos 
desenvolvam habilidades verbais e grande parte consiga desenvolver somente habilidades não verbais de comunicação.

A utilização do brinquedo favorece contato, tornando se objeto de expressão da criança, no qual irá se expressar suas fantasias, desejos e experiências reais, de forma simbólica. Portanto, o brincar é fundamental para o desenvolvimento da criança, no que se refere aos aspectos do crescimento, da saúde e socialização, além de ser uma forma de o sujeito se comunicar consigo e com os outros.

Observa-se que o lúdico é importante para o desenvolvimento infantil, pois possibilita a aproximação com os profissionais que fazem parte da sua rotina e seu processo de desenvolvimento, a expressão de sentimentos e emoções, além de favorecer a socialização pelo contato com outras crianças presentes na escola, na comunidade, em casa e outros locais que a criança frequenta. A socialização pode ser feita em atividades como dinâmicas e trabalhos em grupo, jogos, brincadeiras e brinquedos.

A avaliação processual, que é realizada durante todas as atividades, poderá ser mais esclarecedora, pois fornece dados sobre o desempenho do aluno em diversas situações. Essa forma de avaliação facilita o reconhecimento das necessidades dos alunos e permite que o professor redimensione os indicadores de aprendizagem. As observações sobre o desempenho dos alunos constituem ferramentas importantes na adaptação do planejamento. Por fim, os resultados obtidos serão consistentes desde que sejam considerados indicadores de aprendizagens condizentes com a intencionalidade do ensino.

O planejamento e a organização das estratégias para aprendizagem podem variar de acordo com o estilo do professor. Contudo, é preciso que o planejamento tenha flexibilidade na abordagem do conteúdo, na promoção de múltiplas formas de participação nas atividades educacionais e na recepção dos diversos modos de expressão dos alunos.

O educador deverá considerar no planejamento tempo e estratégias para conhecer seus alunos - em especial aqueles que poderão requerer apoios específicos. Para fornecer boa compreensão sobre os alunos e suas condições de aprendizagem, a 
observação precisa utilizar diferentes estratégias e ser feita em diversos momentos da aula. Os critérios de observação devem ser selecionados com base no currículo e nas habilidades que o professor considerou no planejamento.

\section{CONSIDERAÇÕES FINAIS}

Este trabalho procurou mostrar as dificuldades e as irregularidades motoras que a criança com autismo possui, como também a visão que ele tem de seu próprio corpo. Através da compreensão que disfunções motoras podem contribuir para um atraso de linguagem e comunicação, analisamos que o processo de aquisição de habilidades motoras seja desenvolvido de forma que faça parte integrante nos programas de apoio pedagógico para crianças com Transtorno do Espectro do Autismo (TEA).

Para a execução dos objetivos propostos, tornou-se necessário fazer uma reflexão da história e evolução física desde sua origem até os dias atuais, mostrando que é uma disciplina indispensável a qualquer tipo de ensino, que utiliza de meios físicos e naturais para prevenir doenças e que esta disciplina pode possibilitar ao autista, superação em suas dificuldades do cotidiano, conferindo-lhe uma melhor qualidade de vida.

A Educação Física oferece às autistas novas formas de expressão, além de obter um grande benefício à saúde e melhora nas áreas psicomotora, social e cardiovascular, diminuindo comportamentos como: falta de atenção, impulsividade e hiperatividade.

O desenvolvimento desse estudo permitiu ainda avaliar a importância do profissional de educação física no contexto educacional e de desenvolvimento dos autistas, o qual, por meio da prática positiva de atividades físicas atua de modo a melhorar a qualidade de vida e funcionalidade dos portadores desse transtorno.

Frente ao exposto anteriormente faz-se necessário a realização de mais pesquisas relacionadas ao tema para que os profissionais que lidam com estas crianças tenham maior direcionamento durante suas aulas, possibilitando melhor desenvolvimento psicomotor de seus alunos. 


\section{REFERÊNCIAS}

ALMEIDA, I. F. M. Participação de alunos com NEE nas atividades coletivas da escola de ensino regular. (Tese de mestrado) Lisboa: Instituto Universitário de Ciências Psicológicas, Sociais e da Vida - ISPA; 2015. Disponível em: $\langle$ http://repositorio.ispa.pt/bitstream/10400.12/3972/I/I9775.pdf〉 Acesso em: o8 mai. 2016.

WINNICK, J. P. Organização e Gerenciamento de Programas. In: WINNICK, J. P. (Org.). Educação física e esportes adaptados. Barueri: Manole, 2004. p.21-36.

LÔ, E. N.; GOERL, D. B. Representação emocional de crianças autistas frente a um programa de intervenção motora aquática. Revista da graduação, v. 3, n. 2, 2010. Disponível em: <http://revistaseletronicas.pucrs.br/ojs/index.php/graduacao/article/viewArticle/79 02> Acesso em: 07 mai. 2016.

SZABO, C. B. Autismo: um mundo estranho. 2. Ed. São Paulo: EDICON, 1999, 58p.

MARTINS, C. Face a face com o autismo: será a inclusão um mito ou uma realidade?

(Tese de mestrado) Lisboa: Escola Superior de Educação João de Deus; 2012. Disponível

em: 〈https://comum.rcaap.pt/bitstream/I0400.26/2562/I/ClaudiaMartins.pdf〉 Acesso em: o7 mai. 2016.

SZABO, C. B. Autismo em questão. São Paulo: MAGEART, 1995, II7p. 